\title{
¿Quantité négligeable o rival terrible?: La imagen francesa de la España primorriverista ${ }^{1}$ Quantité négligeable or Formidable Rival? Primo de Rivera Spain's French Image
}

\author{
Ángel HerRerín LóPeZ \\ Universidad Nacional de Educación a Distancia, Madrid (UNED) \\ aherrerin@geo.uned.es \\ ORCID: 0000-0002-8565-0998 \\ Susana Sueiro SeOANE \\ Universidad Nacional de Educación a Distancia, Madrid (UNED) \\ ssueiro@geo.uned.es \\ ORCID: 0000-0002-7972-8488
}

Recibido: 23-11-2016

Aceptado: 15-3-2017

Cómo citar este artículo / Citation: HERRERÍN LÓPEZ, Ángel y SUEIRO SEOANE, Susana (2017). ¿Quantité négligeable o rival terrible? La imagen francesa de la España primorriverista. Pasado y Memoria. Revista de Historia Contemporánea, 16, pp. 17-45. https://doi.org/10.14198/PASADO2017.16.02

\section{Resumen}

Los informes diplomáticos emitidos desde la Embajada de Francia en España durante la Dictadura de Primo de Rivera hacían hincapié en dos asuntos que acaparaban la atención de la Europa de entreguerras: la cuestión de Marruecos, en la que, además de los intereses coloniales nacionales, estaban en juego los intereses geoestratégicos

${ }^{1}$ El presente trabajo se enmarca en el proyecto de investigación del Plan Nacional I+D+I del Ministerio de Economía y Competitividad, "España en la crisis del sistema liberal: una perspectiva externa, 1917-1936", Ref. HAR2012-31460, con una duración de tres años: enero 2012 a diciembre de 2015, y cuyo investigador principal es el profesor Dr. Hipólito de la Torre Gómez. 
de las potencias mediterráneas, y muy en concreto los intereses expansionistas de la Italia de Mussolini, y el miedo al comunismo, que influyó en la deriva autoritaria de buena parte de los países europeos. El presente artículo pretende analizar dichos informes desde la perspectiva de la imagen de España que proyectaban embajadores, cónsules y agregados, ya no sólo como fuente para entender la toma de decisiones de los gobiernos de la metrópoli, sino también para obtener otra visión, siempre a tener en cuenta, de los acontecimientos internos de nuestro país.

Palabras clave: Dictadura Primo Rivera, Marruecos, Comunismo, Francia, España, Siglo XX.

\section{Abstract}

The diplomatic reports issued from the French Embassy in Spain during Primo de Rivera's dictatorship emphasize two affairs that capture the attention of Inter-War Period Europe: First, the Morocco issue, in which both national colonial interests and geo-strategic interests of the Mediterranean powers were at stake, specially the expansionist interests of Mussolini's Italy. Second, the fear of communism, which had an influence on the drift towards authoritarianism of most European countries. The aim of this work is to analyse those reports from the perspective of the image of Spain projected by ambassadors, consuls and attachés, not only as a source for understanding the decision-making process of the French governments, but also as a way of obtaining a new viewpoint, always to be taken into account, of the country's domestic events.

Keywords: Primo Rivera's Dictatorship, Morocco, Communism, France, Spain, $20^{\text {th }}$ Century.

En abril de 1922, la embajada francesa, en un dossier general sobre los problemas sociales en España, señalaba que la salida al régimen político imperante en nuestro país pasaba por un gobierno autocrático, ya fuera monárquico o bolchevique. El régimen republicano, continuaba el informe, "con sus libertades, no puede, en efecto, concebirse en un país donde la educación democrática de las masas está por hacer", donde la clase media no existía, la población era "profundamente ignorante" y se mantenía unida a los privilegios regionalistas, y donde, en definitiva, la "opinión pública" era inexistente. El dossier señalaba las semejanzas entre la España de la Restauración y la Rusia zarista, y, por lo tanto, los riesgos de que la propaganda revolucionaria enraizara en nuestro país. De hecho, la representación diplomática de la Francia republicana llegaba a decir que esperaba un gobierno monárquico fuerte que evitase la victoria bolchevique ${ }^{2}$. Así que el miedo a la expansión del comunismo, tan presente en este período en Europa, era una de las dos grandes preocupaciones del país vecino en relación con España; la otra preocupación era, irre-

${ }^{2}$ Dossier general sobre cuestiones sociales en España, 28-4-1922 Archives du Ministère des Affaires Etrangères, París (en adelante AMAE), serie Z, cartón 267. 
misiblemente, la llamada "cuestión marroquí", lo que incluía la presencia de España en el escenario internacional.

\section{Hispanofobia desde la "grandeur" imperialista}

En los informes de los diplomáticos franceses es muy palpable la escasa consideración que les merece España como potencia, la idea de que es una nación que no puede ser tratada como una igual sino como una quantité négligeable (una entidad desdeñable), insignificante en el escenario internacional a causa de su debilidad política y militar. Sin duda, al final de la Restauración, España era un país débil en una permanente crisis política -partidos disgregados en facciones, gobiernos inestables de escasa duración, un rey demasiado dispuesto a intervenir en el juego político, un ejército demasiado dispuesto a inmiscuirse en la esfera del poder civil... - y no cabe duda de que, si a principios de siglo había logrado participar en los tratados internacionales para el reparto de Marruecos, había sido sobre todo por el interés de Gran Bretaña en que sirviera de contrapeso al expansionismo francés, pero siempre en calidad de potencia menor y desde una posición ciertamente poco privilegiada.

La visión francesa de la inferioridad española no solo se evidencia en los hechos, en la práctica de las negociaciones, en las que España apenas es tenida en cuenta, y en ocasiones ni siquiera es informada, sino también en el trato, en las actitudes de desdén. Como asegura la historiadora hispanista francesa Andrée Bachoud, refiriéndose a los años diez:

"Se hace esperar a sus embajadores, se les aparta de las conversaciones internacionales, se omite informarles de sus resultados. La prensa casi en su totalidad secunda esta amplia campaña de denigración" (Bachoud, 1988: 50).

Esa visión desde el poder acaba contagiando a la opinión pública, incluso a la obrera, como nos relata el anarquista Anselmo Lorenzo (1923: 123) tras años de estancia en Francia:

"Por efecto de una tendencia generalmente sostenida por las clases directoras en Francia, no sólo se han creído los franceses el pueblo superior, sino que tienen como bárbaros a todos los nacidos a la parte opuesta de sus fronteras, especialmente a los españoles. Desde que un escritor francés dijo que África empieza en los Pirineos y otros muchos escritores lo confirmasen (...), la opinión francesa en general cree que España es un país de frailes, manolas y toreros, que pasa el tiempo en misa, o tocando la guitarra, bailando y repiqueteando las castañuelas".

Esto mismo puede decirse para los años veinte. La correspondencia de los diplomáticos franceses está llena de comentarios despectivos y muchas veces sarcás- 
ticos. Es una visión de España que puede calificarse de hispanófoba e incluso, según algún autor, como la propia Andrée Bachoud, de racista. Se basa en un claro sentimiento de superioridad cultural, económica, militar, etc. (Allain, 1976: 303).

Y si eso es así con los diplomáticos de la embajada en Madrid, los juicios de las autoridades francesas en Marruecos son aún más denigrantes. Se refieren a los españoles con calificativos como atrasados, malos colonizadores, ineptos, bárbaros, expoliadores y otros epítetos parecidos. No cabe duda de que la indecisa y vacilante política marroquí de los gobiernos constitucionales, sin que ninguno de ellos se atreviera al abandono de la penosa empresa marroquí pero tampoco a una acción decidida de conquista, costó muy cara y sería una de las principales causas del hundimiento del régimen liberal. Los franceses insisten muy a menudo, no solo en la incapacidad y desidia colonial de España sino en los métodos crueles que utiliza. El desprecio hacia la proyección exterior, y en concreto colonial, de España, es generalizado ya que se trata de una visión que afecta a diplomáticos, políticos, militares y periodistas. Al hacer un repaso de la prensa francesa nos encontramos con afirmaciones como ésta de La Dépêche Marocaine de Tánger:

"España es un país caótico y sin recursos, más propio para ser intervenido por una potencia de superior cultura que para llevar su civilización a otro continente, más apto para ser colonizado que para colonizar. Es horrible -añade- ver a una nación que pretende parecer civilizada y civilizar a otra, usando con ésta métodos que repugnarían a los pueblos más salvajes"3.

La visión que desde Francia se tiene de España está enormemente mediatizada por la cuestión colonial, y muy en concreto por la cuestión marroquí. Cualquier análisis de las relaciones hispano-francesas en el primer tercio del siglo XX tiene que partir de la importancia del tema marroquí (Denéchère, 1999). La amistad y la pretendida colaboración entre ambos países en su calidad de socios de protectorado fue solo "un tópico de banquete" 4 . Si en los discursos oficiales se hacían brindis por las buenas relaciones entre Francia y España, en realidad habían sido, y siguieron siendo en los años veinte, incluso durante la época de colaboración militar tras ataque de Abd-el-Krim a los franceses en la primavera de 1925, unas relaciones tensas, de gran recelo y suspicacia, en gran parte a propósito del tema marroquí.

Esta actitud francesa tiene por supuesto un profundo eco en España. Políticos, militares, diplomáticos, periodistas y desde luego el Rey, protestaron amar-

${ }^{3}$ La Dépêche Marocaine, Tánger, enero de 1922.

${ }^{4}$ Véase La Correspondencia Militar, editorial, 11-4-1923. 
gamente por lo que juzgaban como un trato despiadado ${ }^{5}$. Se quejan de desplantes, desaires, descortesías, menosprecio, del "morbo colonial hispanófobo", de la "guerra de alfilerazos", de la "acrimonia y hasta la marcada malquerencia" en frase de un subsecretario de Estado. El gobierno español emprende con frecuencia reclamaciones a través del embajador de España en París, Quiñones de León.

Para tratar de entender la visión que los diplomáticos franceses tienen de España durante los años veinte hay que retrotraerse a comienzos del siglo XX en que se produjo el reparto colonial de Marruecos y analizar la historia de las relaciones franco-españolas desde entonces. Uno de los más poderosos grupos de presión de la Tercera República francesa fue el partido colonial o "colonista", con un peso decisivo en la política exterior francesa durante más de veinte años. Entre los más destacados miembros del partido colonista estaba Louis Hubert Lyautey, que obtuvo carta blanca del gobierno de París para llevar a cabo la expansión francesa en Marruecos. Un Marruecos totalmente francés era su indudable aspiración. Fue Gran Bretaña quien insistió en que la zona norte tan próxima a Gibraltar quedase en manos de una potencia menor como España, pero en las sucesivas negociaciones sobre el reparto de Marruecos, a principios del siglo XX, España fue perdiendo paulatinamente rango colonial, no solo en virtud de la superficie adjudicada -que se vio gradualmente reducida- sino también por lo que respecta a su estatus jurídico, ya que sufrió un creciente grado de subordinación con respecto a Francia. Por fin, el tratado de 1912 que estableció el Protectorado hispano-francés, consolidó la supremacía francesa. Francia se aseguró en Marruecos una posición de claro predominio, tanto en virtud de sus relaciones con las otras potencias europeas, como de sus relaciones, igualmente privilegiadas, con el Sultán, que aceptó ser su protegido. A pesar de que la autoridad del Sultán no era reconocida por gran parte de las tribus marroquíes, los tratados consagraron el principio de la soberanía del Sultán sobre la totalidad del imperio jerifiano, un Marruecos único e indivisible, lo que significaba que Francia, como protectora y representante del Sultán, ejercería su influencia sobre todo el imperio marroquí. Garante de la unidad de ese imperio, Francia cedía a España una porción de territorio al norte para que la administrara, relegándola a un papel de subarrendataria. Los gobiernos españoles difícilmente aceptaron esta interpretación francesa aunque,

\footnotetext{
${ }^{5}$ Véanse, por ejemplo, los comentarios de Julio López Oliván señalados por el periodista francés Léon Rollin en su informe sobre su viaje a la zona española de Marruecos en septiembre de 1923. AMAE, Europe 1918-1929, Espagne : 53.

${ }^{6}$ Espinosa de los Monteros a Quiñones de León. Madrid, 28-6-1924. Archivo General de la Administración (en adelante AGA), Asuntos Exteriores, 6329.
} 
aislados internacionalmente, no tuvieron más remedio que consentir una posición dependiente con respecto a Francia. Por su parte, en Francia no se perdió ocasión de recordarles el papel subalterno que debían conformarse con desempeñar (Sueiro Seoane, 1992).

Tras la Gran Guerra, a partir de 1919, el poder de los colonialistas franceses fue en aumento. Se produjo entonces una especie de apoteosis colonial en Francia, el sentimiento de orgullo colonial se extendió, ya no solo entre la elite gobernante, sino entre la masa popular. La opinión pública se entusiasmó con la idea del gran Imperio francés ${ }^{7}$. Desde este clima de deseo de engrandecimiento y orgullo colonial, se veía a España como un estorbo en Marruecos.

\section{El todopoderoso Lyautey, creador de imagen y de opinión con respecto a España}

La decidida voluntad expansionista de Francia en Marruecos tuvo a su máximo representante en el mariscal Lyautey, que al constituirse el protectorado en 1912 fue nombrado Residente General en Rabat. Fue él quien marcó la política francesa hacia España en Marruecos. Hasta finales de 1925 tuvo un inmenso poder y una gran autonomía de actuación con respecto al gobierno de París. Lyautey se negó a colaborar con España en las tareas de protectorado. Su convencimiento, como el del partido colonial, era que España no sería capaz de llevar a cabo el esfuerzo necesario para establecer y mantener su zona de protectorado y tendría que acabar por renunciar a favor de Francia. "Desde los orígenes del protectorado -dice Delaunay (2010: 528) - el más virulento de los anti-españoles fue el propio Lyautey". "Consideró a los españoles unos intrusos incapaces de mantener su rango de co-ocupantes".

Lyautey siempre creyó que una colaboración con España, por poco importante que fuese, era absolutamente contraria a los intereses franceses. En cada ocasión en que entre Madrid y París se trató el tema de la posible concertación en Marruecos, él escribió alarmado a su gobierno rechazándola rotunda y categóricamente, llegando a afirmar, en un informe secreto, que la tranquilidad de la zona francesa dependía estrechamente de la agitación que reinaba en la española.

Tras el desastre de Annual en el verano de 1921, Lyautey volvió a escribir a su gobierno afirmando que estaba convencido de que el movimiento rifeño

\footnotetext{
${ }^{7}$ No puede perderse de vista el importante papel desempeñado en la guerra por las colonias; más de 200.000 soldados indígenas murieron en los teatros de operaciones, casi un millón de habitantes de las colonias contribuyeron a la victoria trabajando al servicio de Francia.
} 
era un conflicto localizado que no iba dirigido contra la autoridad del Sultán, una autoridad sagrada y respetada, sino únicamente contra el Jalifa de la zona española, que él consideraba una institución artificial. España -asegurabaera el enemigo hereditario de los musulmanes desde los tiempos de la Reconquista. Los informes confidenciales de Lyautey son abrumadores en el desprecio que destilan hacia la acción colonial española. Se muestra persuadido de que la violencia del movimiento rifeño se debe más a la incompetencia de los españoles que a las dotes de Abd-elKrim. Describe la política de España en Marruecos como el paradigma de lo que nunca debe hacer una nación colonizadora. Lo que le ocurre a España en su zona de Marruecos, asegura, no es sino consecuencia de una larga cadena de errores. El líder del Rif dejó claro que su lucha se dirigía solo contra España. Así que Lyautey pensó que, si Francia adoptaba una actitud de simpatía, o al menos de neutralidad benévola con los rifeños en lucha contra los españoles, esa lucha se circunscribiría a la zona española. La benevolencia con que Francia trató a los rebeldes rifeños, dejando que sus agentes se movieran libremente y compraran armas en territorio colonial francés, suscitaba constantes quejas de los gobiernos españoles (Sueiro Seoane, 1990). Lyautey se justificaba ante su gobierno con informes como éste de 1924 en que afirma:

"Yo no puedo hacerles el trabajo a los españoles y ser yo quien reduzca a Abdel-Krim en lugar de ellos. Les creo desde luego incapaces de hacerlo pero, ¿cómo voy yo, solidarizándome con los españoles, a echarme a las espaldas a todo el Rif y perder así todo el beneficio de la política marroquí que hemos seguido desde hace doce años?"'.

La premisa de Lyautey, que marcó siempre su política y le llevó a desvincularse por completo de España, e incluso a entorpecer la acción colonial española, era que mientras las tribus marroquíes estuviesen empeñadas en su lucha contra los españoles, dejarían en paz a la zona francesa. Esta consideración se demostraría equivocada ya que, en abril de 1925, Abd-el-Krim atacó también y con extrema dureza al protectorado francés, obteniendo un éxito arrollador que hizo temer la caída de la propia Fez, capital religiosa del imperio. Fue entonces y solo entonces cuando Francia pidió celebrar una conferencia con España para acordar una estrategia frente al enemigo ahora común. Lyautey acabó cayendo en desgracia, mientras se imponía la estrategia militar a ultranza del mariscal Pétain. No se produjo, sin embargo, un idilio repentino entre Francia

${ }^{8}$ Nota privada del Mariscal Lyautey al comandante de Cuverville. Rabat, 4-3-1924. AMAE, Europe 1918-1929, Espagne: 49. Los entrecomillados de Lyautey en este texto están extraídos de este extenso informe. 
y España. La lógica obligaba ahora a Francia a una colaboración militar con España, pero las desavenencias durante aquella etapa de colaboración, entre finales de 1925 y 1927, fueron constantes y en más de una ocasión estuvieron a punto de romper la conjunción de esfuerzos.

Desde el comienzo de la Dictadura, los diplomáticos franceses percibieron con claridad el sentimiento francófobo que se había ido generando en España. Tras el desastre de Annual, la presencia en Marruecos se había convertido en una terrible pesadilla para los sucesivos gobiernos españoles. "El avispero marroquí" consumía los recursos humanos y materiales de España y emponzoñaba su crisis política. Al tiempo que el panorama en el Marruecos español se ennegrecía y los gobiernos se veían compelidos a una actuación crecientemente militar, crecía también el sentimiento de animadversión contra Francia. En 1923 el embajador francés calificaba de "enfermizo" el exaltado sentimiento contra Francia que se respiraba en todas las esferas donde se discutía de política. En sus informes se refiere insistentemente a la verdadera psicosis anti-francesa que embargaba a la opinión española. El resentimiento, el rencor hacia la república vecina, había calado progresivamente en la sociedad hasta adquirir, a comienzos de los años veinte, un carácter profundo, impregnando también a sectores liberales que habían sido aliadófilos durante la Gran Guerra.

Léon Rollin, redactor de Le Matin, periodista muy influyente, con contactos estrechos con la Embajada francesa en Madrid, al que se eligió para un viaje por la zona española en septiembre de 1923, redactó a su vuelta un largo informe en el que aseguraba: "Para la gran mayoría de los civiles y la totalidad de los militares, España está luchando en el Rif contra Francia". Por cierto que, a propósito de la campaña francófoba, que fue uno de los temas que se le encargó investigar, dijo sobre los periodistas españoles:

"No hay nada más fácil que utilizar a un periodista español. El periodista español es, salvo muy raras excepciones, de una ignorancia enciclopédica. Prefiere que le den hecho el texto a investigar. Incluso si no ha sido germanófilo durante la guerra, le pasa como a la virgen del pilar de Zaragoza: no le gustan los franceses".

Desde luego, cuando se iniciaba la Dictadura, la imagen de Francia que transmitía la prensa, así como multitud de libros y folletos sobre la acción exterior y colonial de España, y desde luego, la imagen que se había extendido entre la clase política, el ejército y el Rey, era la de la insufrible prepotencia de Francia,

${ }^{9}$ Léon Rollin, "Viaje a la zona española". Septiembre de 1923. AMAE, Europe 19181929, Espagne: 53. 
una Francia imperialista, empeñada en regatear a España sus modestas pretensiones y, en última instancia, en expulsarla del continente africano.

A la impotencia por la guerra rifeña se añadía, además, la cuestión de Tánger. España siempre había considerado una injusta amputación que el enclave tangerino, llave del Estrecho, hubiera quedado excluido de la zona que se le atribuyó en Marruecos. Sin embargo, las grandes potencias de la época, Gran Bretaña y Francia, consideraron que la permanente y frustrada aspiración española sobre Tánger era desmedida y estaba fuera de lugar en relación con la escasa importancia internacional de España. En las negociaciones sobre Tánger del año 1923, que dotó a la ciudad de un estatuto internacional, España se vio obligada a renunciar a todas sus demandas. El reconocimiento de un Estatuto internacional fue en realidad la confirmación de la absoluta supremacía francesa. Cargos importantísimos como el de administrador, o el de jefe de la policía, recayeron en franceses. Desde entonces se producirían con frecuencia altercados ya que la mayoritaria población española, la colonia extranjera más importante numéricamente, los consideraba "hispanófobos cien por cien". Los ánimos españoles estaban siempre excitados y propicios a suscitar incidentes por el agravio que suponía un Estatuto que había echado por tierra sus ilusiones. La prensa española arremetía señalando que, bajo todos los puntos de vista, la internacionalización de Tánger era una aberración, un atentado contra las leyes de la geografía, una coacción moral y material contra España, una cuña clavada en el corazón de su zona, un balón de oxígeno para la rebelión rifeña, etc. (Sueiro Seoane, 1988; 1989; 2013a).

Los diplomáticos franceses despachaban en sus informes el tema de la francofobia española recurriendo a teorías psicológicas. España tenía la necesidad psicológica de encontrar un culpable externo a quien poder achacar su desastrosa realidad colonial. Ante la decepcionante realidad a que había quedado reducido el sueño español de una importante posesión africana que viniese a reparar el prestigio internacional tan dañado tras el desastre del 98, lo más fácil para España era culpar a Francia. Psicológicamente -insisten- es explicable la tendencia a atribuir el fracaso propio a una conspiración extranjera, dada la dificultad de asumir el descrédito que supone "que una nación dotada de los instrumentos de guerra creados por la ciencia europea sufra una espectacular derrota por parte de tribus bereberes atrasadas" 10 .

También afirmaban que era Alfonso XIII, mucho más que Primo de Rivera, quien expresaba el sentimiento de frustración. La visión de los diplomáticos

${ }^{10}$ El embajador francés en Madrid, Fontenay, al ministro de Negocios Extranjeros, Poincaré, 1-5-1924. AMAE, Europe 1918-1929, Espagne: 54. 
franceses en los años veinte era que el monarca, al que se describe muy certeramente como excesivamente locuaz y muy deseoso de intervenir de forma decisiva en los asuntos políticos, se mostraba siempre más francófobo que el dictador; desde muy pronto, antes ya del golpe de Primo de Rivera, se refieren a "sus veleidades de poseer mayores medios militares con miras a apoyar alguna combinación política más audaz en la política exterior”. El Embajador señalaba que Alfonso XIII se había tomado la solución dada al asunto de Tánger en 1923 como una ofensa personal que había determinado su negativa a asistir a varios actos franceses en Madrid, y su decisión de anular su tradicional viaje anual a Burdeos:

"Alfonso XIII pensaba que Tánger debía incorporarse a España. Los acontecimientos no le han dado la razón, lo que ha supuesto para él una amarga decepción, que evidentemente ha influido en sus sentimientos hacia nosotros. Quiero creer que este enfriamiento sentimental no durará mucho: España en el futuro puede tener necesidad de Francia y su joven e inteligente Rey lo sabe. Si yo me preocupo por este enfado es porque no convendría que el Soberano estuviera todavía bajo esta impresión cuando dentro de unas semanas reciba la visita de los Reyes de Italia, acompañados de Mussolini”"11.

\section{El temor a una alianza de España e Italia}

La idea de que la frustración respecto a Francia pueda llevar a España a emprender una vía nueva en política exterior, mediante una alianza políticomilitar con la Italia de Mussolini, está muy presente en los informes diplomáticos franceses a lo largo de los años veinte. En la cancillería francesa se siguió muy de cerca el proceso de aproximación ítalo-española ya que no era ningún secreto su carácter anti-francés, o al menos su propósito de contrarrestar la hegemonía francesa en el Mediterráneo. Desde luego, desde la óptica francesa, era una relación desigual ya que "al vigor italiano", se oponía "la debilidad española"; "en este terreno, como en otros, se consagra la flagrante inferioridad de España"12. Sin embargo, España, en sí misma insignificante como potencia, podía prestar a Italia sus recursos geoestratégicos. Es su posición en el mapa, su situación privilegiada sobre el Estrecho de Gibraltar, paso obligado para gran parte de la navegación mundial, el activo con que cuenta.

${ }^{11}$ El embajador francés en Madrid, Fontenay, al ministro de Negocios Extranjeros, Poincaré, 2-4-1924: "Posible transformación del papel que puede jugar España". AMAE, Europe 1918-1929, Espagne: 54.

${ }^{12}$ Corbin a Poincaré. Madrid, 28-11-1923, No 644, "El viaje a Roma y la política ítalohispano-americana". AMAE, Europe 1918-1929, Espagne: 53. 
La posibilidad de un acuerdo hispano-italiano en el Mediterráneo era un asunto que la Embajada francesa llevaba siguiendo con detalle desde el final de la Gran Guerra. Santiago Alba como ministro de Estado del último gobierno constitucional se quejó de que Francia ignoraba por completo su oferta de una acción concertada en Marruecos y se mostró interesado en atender las propuestas de aproximación que le llegaban de Roma. Fue Alba quien decidió que los reyes españoles viajaran a Italia en el mes de noviembre de 1923. Como entre tanto se produjo el golpe de Estado de Primo de Rivera, el dictador decidió acompañar a los reyes españoles en aquel resonante viaje. Desde ese momento, el gobierno de París pidió a sus embajadores en Roma y Madrid que investigaran con detalle el acercamiento entre las dos penínsulas mediterráneas y la posibilidad de que pudiesen suscribir, o hubiesen suscrito ya, un acuerdo naval o militar secreto. Tanto el embajador como los agregados naval y militar franceses dedicaron mucha tinta a analizar las relaciones entre Primo de Rivera y Mussolini (Tusell y Saz, 1982; Palomares, 1989; Sueiro Seoane, 1992; 2005; 2013b).

La incógnita era si España llegaría a suscribir una alianza con Italia que supusiera un claro desafío al statu quo vigente. Al contemplar esta posibilidad, los diplomáticos franceses manejaron dos imágenes de España, en gran medida contrapuestas, a las que se refieren insistentemente. Por una parte, la de su deseo de preservar su tradicional neutralidad y la escasa disposición a correr los riesgos inherentes a una alianza político-militar. Por otra, la de ser un país loco e irracional. El encargado de negocios, que estuvo al frente de la Embajada en los días posteriores al viaje de los reyes y Primo de Rivera a Italia, afirmaba:

"España se siente poco dispuesta a las aventuras; por el momento le basta con su reorganización interna, que absorbe toda la atención del Directorio y con las dificultades que sufre en Marruecos. (...) El deseo que este país podría tener de ocupar un puesto más importante en las cuestiones mediterráneas se subordinará siempre a la preocupación por proteger su neutralidad"13.

"Hay que convencerse -dice por su parte el agregado militar- de que España es esencialmente neutral y no aceptará a ningún precio comprometerse en una aventura que podría, un día, imponerle sacrificios. El de Marruecos le basta y le sobra" ${ }^{14}$.

${ }^{13}$ Corbin a Poincaré. Madrid, 24-11-1923. "Acuerdo ítalo-español de 1887. Política general de España, despacho No 648. AMAE, Europe, 1918-1929: 53.

${ }^{14}$ Agregado militar francés a su gobierno. Madrid, 17-4-1924: "El acercamiento hispano-italiano". AMAE, Europe 1918-1929, Espagne: 54. 
Los franceses veían con claridad que era Mussolini el que había solicitado la firma del acuerdo secreto. Primo de Rivera se había dejado querer, pero no se había atrevido a firmar nada que modificase la tradicional política española consistente en estar bajo el paraguas de la entente franco-inglesa:

"España, que parece inconsolable por haberse convertido en una potencia de segundo orden, nos hace gustosamente responsables del olvido en que se encuentra. Ahora nos lanza una mirada triunfal porque se cree a punto de representar un papel en la política mundial"15.

La interpretación que hacen los diplomáticos franceses es que el dictador español pretende darles un toque de atención, intimidarles un poco para lograr que se le tenga en cuenta en las cuestiones mediterráneas, demostrándoles que cuenta con buenos amigos. Pero en ningún caso desea asumir riesgos excesivos. Tratan de convencerse de que, a pesar de la admiración que Primo de Rivera siente por Mussolini, España no tiene miras imperialistas. Cuando en 1924 se vio que el viaje que los reyes de Italia hicieron a España para devolver la visita de 1923 no revestía la pompa de aquel, sino que se trató de una visita protocolaria, sin la presencia de Mussolini, el embajador señalaba aliviado que Primo de Rivera había optado por la prudencia:

"Ha comprendido el peligro que entraña (una alianza con Mussolini), se ha dado cuenta de que España no tiene por qué buscar comprometerse en arriesgadas empresas para las que ni su Marina, ni si Ejército ni sus finanzas, ni su opinión pública están preparados. No hay en España fascistas ávidos de conquistas y de engrandecimiento territorial; se limitan aquí en confiar con poner fin a la resistencia de Abd-elKrim y, en el interior, a extirpar los principales abusos que han conducido a España al estado deplorable en que se encuentra. Se desea vivir en paz con los vecinos, sobre todo con Francia cuya vecindad se vuelve cada día más cercana"16.

Al referir cómo, durante la visita de los monarcas italianos a España, la proyección de una película de propaganda sobre Mussolini en un cine de Madrid no tuvo mucha repercusión ("el cine estaba medio vacío"), asegura el embajador:

"Es que el público español no comprende la dictadura al estilo del Duce. España no se recrea en las manifestaciones grandilocuentes, belicosas e imperialistas de su hermana latina; para ella la dictadura del General Primo de Rivera será siempre un gobierno de paz interior poco amenazador para sus vecinos y con

\footnotetext{
${ }^{15}$ Corbin a Poincaré. Madrid, 24-11-1923. AMAE, Europe, 1918-1929: 53.

${ }^{16}$ Fontenay a Poincaré. Madrid, 25-5-1924, no 372: "Visita de los Soberanos italianos a España". AMAE, Europe 1918-1929, Espagne: 54
} 
algunos lados campechanos y a veces incluso ridículos, de los que los españoles son los primeros en burlarse" 17 .

Pero, por otra parte, los diplomáticos franceses recuerdan con frecuencia el carácter impulsivo de los españoles, que pueden dejarse arrastrar a una acción disparatada movidos por un espíritu de revancha. Ese retrato del español como un "niño grande", imprevisible, inconsecuente, difícil de manejar, capaz de cualquier locura, está muy arraigado en la visión francesa. Frente al francés racionalista, el español es el ser apasionado que puede dejarse llevar por las emociones hacia una acción irracional. En los años veinte, igual que diez años antes, los diplomáticos franceses seguían señalando la tendencia española a los "prontos", las "boutades" 18 , las acciones poco meditadas.

Desde el punto de vista francés, el momento de mayor irracionalidad, desafío y rebeldía en el transcurso de la Dictadura fue 1926. Tras el desembarco de Alhucemas, con la colaboración francesa, y la posterior campaña militar, se consiguió la rendición de Abd-el Krim y con ello Primo de Rivera obtuvo el éxito más rotundo de su dictadura. Eufórico y deseoso de aumentar el prestigio de España, lanzó entonces su gran batalla diplomática, planteando dos reivindicaciones: la incorporación de Tánger a la zona española de Marruecos, y un puesto permanente en el Consejo de la Sociedad de Naciones (SdN), aprovechando las discusiones para el ingreso de Alemania. Como señalaba Primo en una de sus habituales notas oficiosas:

"Al teatro del mundo no puede asistir España, la gloriosa España, madre de cien pueblos, a anfiteatro, ni siquiera a butaca; debe ir a palco. Si se le confía un protectorado, debe ser sin mutilación, y si se considera que es útil en la Sociedad de Naciones, debe figurar en el rango de las grandes potencias"19.

La cancillería francesa, como por lo demás la inglesa, vio en estas reclamaciones una ilusión desmedida y de imposible realización. Se acusó a los españoles de no tener sentido de la realidad, de no ser capaces de percibir el abismo existente entre sus reivindicaciones y el peso real de su país en la escena internacional. Se les reprochó irracionalidad al plantear unas demandas desorbitadas que no se ajustaban a la débil posición de España en el concierto europeo. Pero, además de megalómanos, se les tachó también de burdos y chapuceros al proponer la componenda de renunciar al puesto permanente en la

\footnotetext{
${ }^{17}$ Peretti de la Rocca a Briand. Madrid, 23-11-1926, "Propaganda italiana en España". AMAE, Europe 1918-1929, Espagne: 54

${ }^{18}$ El embajador francés en Roma a su gobierno, 15-4-1924. AMAE, Europe 1918-1929, Espagne: 54

${ }^{19}$ Véase, El Debate, 19-8-1926.
} 
SdN a cambio de obtener Tánger lo que, además de contribuir a enredar las cosas al mezclar dos asuntos completamente diferentes, fue interpretado como un inaceptable chantaje. Esos procedimientos de "mercadería" al subordinar el "mercado de Ginebra al mercado de Tánger" les valieron a los políticos de la Dictadura los duros calificativos de "irresponsables", "intratables", "impresentables", "imposibles", etc.

Como irresponsable se juzgó también la decisión española de retirada de la SdN a principios de septiembre de 1926, al no ver satisfecha su demanda del puesto permanente. Era una palpable muestra de que no podía descartarse una acción imprudente del dictador. Al menos en esta ocasión, España había cumplido su amenaza. En aquel contexto de renovada ofensiva diplomática de la Dictadura, se reavivó con fuerza el tema de la amistad hacia Italia.

Pareció que España hubiese sucumbido a las seducciones italianas cuando se supo que por fin se había firmado en el más estricto secreto un tratado de amistad hispano-italiano. Se habló de la posibilidad de "disposiciones secretas convenidas entre los dos países", "cláusulas que prevén la apertura de los puertos españoles en tiempo de guerra a la flota italiana y la organización de las bases navales, en particular las de Mahón y Palma, que Italia podría utilizar para vigilar las rutas que van de Argelia a Francia", según comentaba el embajador en noviembre de 1926:

"Para Francia las Baleares en manos de Italia, en caso de conflicto bélico, supondría la práctica imposibilidad de mantener sus comunicaciones con Argelia y Túnez, y sabemos que estas comunicaciones son de una importancia vital para nuestra defensa nacional. Pero hay más, España posee en el Atlántico un rosario de pequeñas bases: los submarinos ocultos en las islas Canarias, en Larache, en Vigo... harían muy precarias nuestras comunicaciones con Marruecos occidental y con el África negra"20.

Fue entonces cuando la imagen de país irracional volvió con fuerza en los comentarios de los diplomáticos franceses. Pero, a pesar de la tendencia a la bravuconería y las acciones irreflexivas, la cancillería francesa no creyó nunca de verdad que Primo de Rivera se atreviese a llevar hasta sus últimas consecuencias la amistad con Mussolini. Ahora bien, sí se creyó en París que debían ofrecerse a los españoles "algunas satisfacciones superficiales de amor propio". Tanto las cancillerías como los propios políticos españoles hablan del orgullo español y de lo relativamente fácil que podía ser satisfacerlo. Alfonso XIII aseguraba que los españoles podrían conformarse con unos cuantos halagos, sin pedir más:

${ }^{20}$ Peretti a Briand. Madrid, 16-11-1926. Secreto: "Las tendencias de la política española y la defensa nacional”. AMAE, Europe 1918-1929, Espagne: 54. 
"Cuando se quiere hacer tragar una purga a un niño -afirma- hay dos procedimientos. El primero consiste en taparle la nariz e introducirle en la boca una buena cucharada de aceite de ricino. El segundo es el de enmascararle la purga con un caramelo. Los resultados son idénticos, pero, con el primer procedimiento, el niño aborrece la medicina y al que se la da, mientras que, con el segundo, por el contrario, la encuentra excelente y se siente incluso agradecido por el regalo que se le hace. Con España, Francia adopta la primera forma de actuar cuando hubiera podido adoptar la segunda"21.

Los franceses también se refieren con mucha frecuencia al carácter orgulloso del español y de lo interesante que puede resultar "halagar su amor propio". Lyautey, al ser sondeado en 1923 por su gobierno respecto a un posible cambio de política de Francia hacia España para contrarrestar las evidentes muestras de la aproximación de Primo de Rivera y Mussolini, había accedido cínicamente a ofrecer "salvar la cara", decía, ofreciendo a los españoles "simples cortesías de fachada", por ejemplo un "intercambio de telegramas grandilocuentes".

Léon Rollin, el periodista a quien nos hemos referido, creía, al igual que el embajador francés en Madrid, que Francia debía mostrarse más amable y condescendiente en el trato con su socia de protectorado: "De vez en cuando se deberían hacer visitas, ya sea a iniciativa nuestra o suya; se iría a "admirar" amablemente" porque, señalaba, aunque los españoles reconozcan en los franceses a los maestros colonizadores, "sería conocerles mal el creer que esta subordinación de discípulos a maestros no hiere su amor propio". Se trataría de suavizar la actitud despectiva, pero nada más. A este respecto, el embajador asegura:

"El español tiene una susceptibilidad que nuestro espíritu francés no ha sabido desgraciadamente tener en cuenta. Es hora de poner remedio al mal porque en estos momentos se trata nada menos que de la posible constitución de una alianza mediterránea contra nosotros. (...) Convendría, pues, tratar a España con la importancia que representa para nosotros, y no como un simple anexo de Marruecos"22.

Como vemos, el embajador reconoce que la displicencia francesa es una realidad, y el arraigo de la visión de España como parte de África y no de Europa. Y va más allá, interiorizando esa convicción de que España es una "entidad despreciable" al señalar:

"En realidad, el gobierno italiano conoce perfectamente el verdadero valor militar y naval de España, nulo, pero con gran destreza confiere a esta Corte y a este

${ }^{21}$ Audiencia concedida por el Rey al agregado militar francés, 3-1-1924. AMAE, Europe 1918-1929, Espagne: 54.

${ }^{22}$ Fontenay a Poincaré. Madrid, 8-4-1924. AMAE, Europe 1918-1929, Espagne: 54. 
pueblo la ilusión de verse tratados como potencia importante que puede desempeñar un papel en los acontecimientos mundiales que se avecinan. Nos bastaría, creo yo, actuar de la misma manera, darle a España la impresión de que la tenemos en cuenta, de que nos interesamos por ella, y acaso pudiéramos impedir así que se convirtiese en el juguete y el instrumento de las intrigas del fascismo italiano, que estará fatalmente abocado a hacer la guerra para no desaparecer"23.

Este informe manifiesta con claridad que los diplomáticos franceses consideran que España es una nulidad militar y naval, pero que puede llegar a ser el "juguete" de la Italia de Mussolini. Mussolini, sin embargo, no consiguió su propósito y de hecho se desilusionó bastante pronto ante el "incurable afrancesamiento" de España. Pasado el momento de euforia tras la victoria en Marruecos, Primo de Rivera comprendió que era peligroso rebelarse contra la hegemonía de Gran Bretaña y Francia. Las nuevas negociaciones sobre la cuestión tangerina a las que estas potencias accedieron, no desde luego para dar satisfacción a la demanda española, sino para revisar el estatuto internacional que había mostrado sus imperfecciones, acabó en 1928 sin que España consiguiera nada sustancial, y ese mismo año España regresó al seno de la SdN sin puesto permanente.

La conciencia de inferioridad frente a un vecino mucho más poderoso, que impide a España representar un papel internacional y colonial más activo, crea en los españoles un sentimiento de animadversión y admiración, de antipatía y fascinación, de adversario y aliado. Como señalaba el Nuncio apostólico en Madrid, España se debatía con Francia en una compleja relación amor-odio:

"Existe una curiosa contradicción entre la antipatía que en los españoles llega casi hasta el odio hacia Francia y la fascinación que indiscutiblemente ejerce Francia en la nación española”24.

Aunque más allá de la compleja relación entre Francia y España, con sus filias y fobias, la "cuestión marroquí", sobre la que pivotaba, como hemos visto, buena parte de los intereses de ambos países en el plano internacional, vino a ser determinante para la "solución" de la otra gran preocupación francesa en relación a nuestro país: la expansión del comunismo. Los problemas derivados de la guerra en Marruecos influyeron de forma determinante en el cambio de régimen en España, con la caída del sistema liberal y la instauración de la dictadura de Primo de Rivera. Cambio que supuso una restricción de libertades y

${ }^{23}$ Ibíd.

${ }^{24}$ Medici del Vascello Embajador italiano en Madrid, a Mussolini. Madrid, 1-4-1927. AMAE, Roma, Politica, 1591. 
derechos, y, en consecuencia, un endurecimiento de las condiciones en las que se desenvolvían las fuerzas que apostaban por cambios radicales.

\section{De la continuidad política al miedo comunista}

Las primeras informaciones que salieron de la Embajada de Francia en referencia al golpe de Estado protagonizado por el General Miguel Primo de Rivera hacían hincapié, recogiendo declaraciones del nuevo dictador, en el reemplazo del gobierno de políticos por otro de militares para mantener el orden, la disciplina y el principio de autoridad, porque "los militares no podían tolerar los insultos a la patria y al ejército"25. Aunque varios factores habían influido en el golpe de Estado: la quiebra del sistema político de la Restauración, la destrucción de la concentración liberal, la conflictividad social, el terrorismo..., el factor desencadenante fue la asunción de responsabilidades por parte del Ejército en la guerra de Marruecos. El desastre de Annual supuso un gran desprestigio para las Fuerzas Armadas, que se mantuvo y hasta aumentó con la apertura del expediente Picasso y el posterior procesamiento, por los sucesos de agosto de 1921, de altos jefes y oficiales. Desde julio de 1923, el Senado y el Congreso debatieron sobre esta cuestión, creándose la "comisión de los 21", lo que implicó que las protestas de los militares derivaran en conspiraciones golpistas (Marín, 1991).

Pero el Embajador de Francia en España, Defrance, ponía énfasis en causas más profundas que apuntaban tanto a las características del régimen político existente en España, como a las particularidades e idiosincrasia de la sociedad española. Para Defrance uno de los principales problemas consistía en que el régimen imperante, la Restauración, se caracterizaba por la ausencia de democracia: "El régimen parlamentario es en efecto aquí en cualquier momento una ficción completa", donde reinaba la falta de honestidad política y donde "el principio constitucional es poco respetado". Hasta mostraba su acuerdo con el nuevo dictador cuando decía que "las Cortes disueltas no representan en modo alguno al país". A pesar de esta concordancia con Primo de Rivera, el Embajador aseguraba que el Directorio Militar no dejaba de ser una fachada, pues seguiría buscando su apoyo en los elementos de siempre: "la Corte, el clero y la alta nobleza"; grupos que mantendrían la voluntad de salvaguardar "los intereses de dos o trescientas familias que tienen en España los altos cargos de la Corte, los mejores trabajos". Porque en el fondo la dictadura impuesta era estrictamente personal, y el nuevo Dictador no le parecía "a decir verdad, ser

${ }^{25}$ Telegrama de Defrance, Embajador de Francia, desde Barcelona, 13-9-1923. AMAE, serie Z, cartón 240 . 
un hombre de primer orden". De hecho, sus concepciones en materia gubernamental, según sus declaraciones y dada su personalidad, procedían "de la mente más simplista". De todas formas, el Embajador reconocía que Primo estaba recibiendo adhesiones numerosas y cualificadas. Entre ellas, la de todos los partidos políticos, que se habían pronunciado por la abstención y quedaban a la expectativa. El propio Rey que, según el Embajador, parecía no había tomado parte en el golpe, podría ser uno de los más beneficiados por la nueva situación ya que "dada la impotencia de todos los gobiernos regulares que se han sucedido desde la fase crítica y sangrienta de 1909, el golpe de Estado del General Primo de Rivera era el mejor y puede ser el único medio de salvar el Trono y al País".

Defrance no se mostraba menos crítico con los políticos de la Restauración, a los que calificaba como incapaces y endebles para actuar en contra del Dictador: García Prieto, simbolizaba la debilidad del régimen caído; Alba, la corrupción; Melquiades Álvarez no contaba sino con un apoyo muy reducido; el Conde de Romanones estaba fatigado y hastiado por las luchas miserables e intrigas; Maura, que fue "el campeón del principio de autoridad integral en los límites de la estricta legalidad", censuraba la actuación del General, circunstancia que lo enfrentaba a su partido, que mayoritariamente aprobaba el golpe; La Cierva tampoco era capaz de actuar a pesar de sus apoyos; el menos incapacitado de todos, para el Embajador, era Sánchez Guerra, que antes de la salida del Rey de San Sebastián fue a verle al palacio de Miramar para advertirle de la gravedad de la situación y la importancia de sus decisiones, al tiempo que le pedía recapacitar sobre el papel del Ejército y la Constitución, pues si "el ejército francés, que volvió victorioso de Alemania, respetó el poder civil y la Constitución, no es para que el ejército español, que sufrió más derrotas, actúe de otra manera". Un Ejército que a pesar de las apariencias pudiera no ser el apoyo más seguro del nuevo gobierno, pues no había que olvidar, continuaba Defrance, que en la historia de España los pronunciamientos se habían producido en serie, y un jefe militar suplantaba a otro.

En cuanto a la oposición, Defrance señalaba que los elementos populares, en concreto las fuerzas obreras, estaban "muy dispersas", apenas organizadas y abandonadas en la apatía, que era "una de las características principales del conjunto del país". Apatía que podía ser una de las causas para entender la facilidad con la que el golpe se había impuesto, pero a la que habría que añadir la complicada situación política y social. Así se podía interpretar el apoyo que el dictador había recibido de los centros comerciales, ayuntamientos, 
Cámaras de comercio..., lugares que, según afirmaba, habían sufrido la propaganda anarquista y los atentados sociales ${ }^{26}$.

Así que la importante conflictividad social y los problemas de orden público, que la delegación diplomática francesa unía a la expansión del comunismo, concitaron su atención en las primeras actuaciones del Directorio Militar. El Embajador señalaba que el nuevo régimen había satisfecho desde el principio los deseos de una multitud asustada: se había constituido el Somatén a nivel nacional, se habían suprimido de los tribunales de lo penal a los jurados populares -que eran considerados débiles cuando no aterrorizados por los encausados, lo que influía en la absolución "casi sistemáticamente de los autores de crímenes anarquistas" - y se había juzgado en 48 horas a los autores de un atraco contra la Caja de España en Tarrasa. La ejecución de la sentencia, que había sido de pena de muerte, se había cumplido en la noche posterior a la deliberación del Consejo de Guerra. Pero la intervención contundente del Directorio en relación con los problemas que atravesaban los bancos no se limitaba a la ejecución de los atracadores, sino que, en un claro aviso al movimiento obrero, apoyó el despido de empleados bancarios y obligó a bajar los salarios a niveles anteriores a la huelga mantenida precisamente por dichos despidos ${ }^{27}$.

\section{La división del Movimiento obrero y la importancia de la UGT}

Pero el movimiento obrero estaba muy dividido, y la posición de las organizaciones obreras contra la implantación de la Dictadura fue dispar. Mientras que la CNT y el Partido Comunista hicieron llamamientos a la resistencia popular, que obtuvieron una débil respuesta, el PSOE y la UGT pedían a las clases obreras un tiempo de espera para ver la deriva que tomaba el nuevo régimen (Sueiro, 2002). Aunque el Embajador intuía, desde las primeras semanas, la estrategia que los socialistas iban a seguir durante la Dictadura: por un lado, la colaboración, y, por otro lado, aprovechar la ventaja que ésta les confería ante sus "rivales". Para el diplomático "la posición que El Socialista manifiesta contra el Directorio es todo fachada..., no es de este lado de donde se puede predecir un serio obstáculo para el General Primo de Rivera..., puede ser incluso que no estén lejos de colaborar con el nuevo régimen". Mientras que a la hora de enjuiciar la represión ejercida desde el poder, significaba que los socialistas "sin duda, no sienten ver al Gobierno militar tomar ciertas medidas de rigor contra los comunistas, sus rivales políticos"28.De hecho, el PSOE llevó

\footnotetext{
${ }^{26}$ Informe de Defrance a Poincare, 21-9-1923. AMAE, serie Z, cartón 240.

${ }^{27}$ Informe de Defrance a Poincare, Finances. 28-9-1923.AMAE, Espagne n ${ }^{\circ} 71$, sig. 248.

${ }^{28}$ Informe de Defrance a Poincare, 3-10-1923. AMAE, serie Z, cartón 240.
} 
su posición más allá de nuestras fronteras, y defendió en el Bureau permanente de la II Internacional, en Ámsterdam, que no había lugar "por el momento para tomar una actitud de oposición agresiva contra la Dictadura militar"29.

La predicción se convirtió en realidad, y los socialistas pasaron de la neutralidad a la colaboración con el nuevo régimen. Participaron en el Consejo de Trabajo y en el Consejo de Estado, órgano consultivo de ayuda al Directorio Militar, que contó con la presencia de Largo Caballero. La UGT colaboró también en la organización corporativa creada por el Ministerio de Trabajo. El modelo provenía del sistema corporativo fascista italiano, aunque con diferencias esenciales. La base de la nueva organización eran los "comités paritarios", donde obreros y empresarios discutían sus diferencias. La central socialista impuso como condición para su participación el exclusivismo en dichos comités. De esta forma, no sólo evitó su ilegalización, sino que creció y consolidó su organización; a diferencia de la CNT, que sufrió la represión y el desmantelamiento de sus estructuras (Juliá, 1997: 126-131; Elorza, 1972-1974). Era lo que el Embajador francés, Jean Herbette, en tiempos de la II República, tomando el ejemplo de la colaboración de la UGT durante la Dictadura de Primo de Rivera, denominaba colaboración "naturalmente no exenta de influencia" ${ }^{\text {, }}$ que le permitió crecer al abrigo de la Dictadura.

La Embajada de Francia entendía la importancia que para el nuevo régimen tenía la colaboración de los socialistas. Asunto que no se circunscribía a su integración en diferentes organismos institucionales, sino que era pieza fundamental para la moderación, el control del movimiento obrero y el mantenimiento del orden público. Como señalaba el embajador Peretti, desde el gobierno no se dudaba en hacer promesas a la central socialista cuando se sentía "la amenaza de un conflicto entre el capital y el trabajo"31. Colaboración que no siempre fue correspondida desde la Dictadura, como sucedió con la principal Fiesta del Trabajo: el $1^{\circ}$ de Mayo. Primo de Rivera no permitió la celebración en libertad de este día durante su régimen. En la primera celebración, en mayo de 1924, ante las promesas del Dictador de permitir los actos programados, las direcciones del PSOE y la UGT llamaron a la participación obrera manteniendo "su cordura y sensatez"32. Sin embargo, Primo se desdijo de lo prometido y prohibió la manifestación. Lo que no impidió que desde El Socialista se llamara a la responsabilidad, a la educación de clase y a "la disciplina aplicada a las organizaciones obreras, que, conscientes de su respon-

\footnotetext{
29 Telegrama de Defrance a Poincare, 7-10-1923. AMAE, serie Z, cartón 240.

${ }^{30}$ Informe de Jean Herbette a Paul Boncour, 4-1-1933. AMAE, serie Z, cartón 258.

${ }^{31}$ De Peretti a Briand, 23-6-1926. AMAE, serie Z, sig. 124.

${ }^{32}$ El Socialista, 10-4-1924
} 
sabilidad, saben usar sus derechos y aún a veces ceder de ellos", a diferencia de aquellos que aplicaban "métodos terroristas", en clara alusión a la $\mathrm{CNT}^{33}$. Para una vez pasada la celebración señalara que la Fiesta del Trabajo había triunfado a pesar de todos sus enemigos, sin especificar quiénes eran, al tiempo que se significaba, con un triunfalismo difícil de interpretar, que "la jornada de ayer quedará en nuestros recuerdos como una de las más salientes, más gloriosas" 34 .

La prohibición de celebrar el $1^{\circ}$ de Mayo se mantuvo durante toda la Dictadura. Desde la Dirección General de Seguridad se puso un celo especial en evitar el paro característico de la jornada, llegando a la coacción, y se prohibieron las manifestaciones, alegando que el gobierno no podía autorizarlas porque podían impedir el cumplimiento de la jornada laboral. Por su parte, los socialistas mantuvieron durante todo este período la misma actitud: acatamiento de la decisión gubernamental y llamadas a la responsabilidad de los trabajadores, para que la jornada se desenvolviera en orden, aunque nunca renunciaron a la convocatoria del paro (Rivas, 1987; Herrerín, 2010). En estas circunstancias, no es de extrañar que los informes que llegaban de la Embajada de Francia en España a París, en las celebraciones del $1^{\circ}$ de Mayo, incidieran en "la calma más absoluta", en la "calma completa", o en significar que los obreros habían aprovechado esta jornada para ir a comer al campo ${ }^{35}$. Informes del Embajador Peretti que eran refrendados, en este extremo, por el agregado militar en la Embajada francesa en España cuando insistía en que en la Península había "calma, orden y tranquilidad". Aunque a la hora de enjuiciar la situación política y social de nuestro país y la visión que tenía de los españoles era mucho menos comedida que la del Embajador francés.

\section{Los españoles y el comunismo}

En un documento que llevaba por título: "La situación interior de España y las intrigas revolucionarias", el agregado militar señalaba que las masas populares mostraban, desde el punto de vista político, "la más perfecta indiferencia", por lo que "sería un error completo creer que el pueblo español reclama..., poder expresar libremente su opinión política..., el ejercicio del derecho de voto no representa, para él, más que una ocasión propicia de vender su voz a un precio ventajoso y de realizar una buena operación comercial". En relación con el problema de los separatistas catalanes y vascos, difería de la opinión que

${ }^{33}$ El Socialista, 30-4-1924.

${ }^{34}$ El Socialista, 2-5-1924.

${ }^{35}$ Informes de Peretti a Briand, 3-5-1925 y 3-5-1926. AMAE, serie Z, cartón 240. 
aparecía en la prensa extranjera, pues, según su opinión,"en estas provincias la inmensa mayoría de la opinión es netamente opuesta al separatismo", aunque fueran muy numerosos los que reclamaban una mayor autonomía y el mantenimiento de sus fueros. Lo que le permitía ironizar para marcar diferencias entre países, pues "mientras que en Francia hemos hecho revoluciones para suprimir privilegios, en España se hacen para conservarlos".

El análisis que hacía de los viejos políticos españoles tampoco tenía desperdicio: "Sus líderes son jefes sin tropa", porque la opinión pública sabía demasiado bien que "la mayoría de ellos no buscan más que el poder para satisfacer sus apetitos personales". Por su parte, los republicanos no representaban más que una ínfima minoría, sin organización e incapaz de figurar como partido de oposición. Mientras que los intelectuales eran, en apariencia, los adversarios declarados del Directorio. Pero España era uno de los raros países de Europa "donde esta clase social no tiene ninguna influencia en la opinión". Así que, aunque pueda parecer una contradicción, la oposición a la Dictadura presidida por un General podía venir del propio Ejército, siempre que hubiera numerosos descontentos: "La Historia prueba, en efecto, que en España un pronunciamiento engendra generalmente otro"; porque, continuaba el agregado militar, los oficiales del Ejército de África no perdonaban al Dictador la evacuación de Marruecos, pero no porque su patriotismo estuviera herido, sino porque veían que les privaba de una fuente de beneficiosas remuneraciones. En definitiva, concluía que la situación política indicaba que, a pesar de cierto malestar, los adversarios estaban muy divididos, sin organización y sin la fuerza necesaria para derrocar al régimen. La única posibilidad podía ser la repatriación del Ejército de Marruecos, cuyos descontentos podían aportar los elementos de fuerza de los que carecían los partidos en la actualidad. Aunque el agregado terminaba aventando el miedo a la revolución, y advirtiendo que parecía más lógico pensar que sería el comunismo el que los proporcionaría.

Elementos de fuerza que, según el agregado militar, no dejaban de llegar mediante la propaganda clandestina intensa procedente de Moscú, que buscaba explotar, entre los soldados y obreros (para formar los soviets españoles a imagen de la revolución bolchevique) el descontento provocado por la campaña de Marruecos y la carestía de la vida. Pero la expansión del comunismo en nuestro país iba más allá de las circunstancias del momento. El plan de acción de los Soviets en la Península parecía contar con la idiosincrasia del país. Lo que no dejaba de ser la utilización de los tópicos que sobre el pueblo español se han venido esgrimiendo para justificar la imposibilidad de los españoles de vivir en democracia: "El pueblo español es un pueblo primitivo, sin instrucción 
y sin la menor educación política", es dócil y sumiso cuando siente por encima de su cabeza la mano firme de la autoridad, pero si esta afloja, da salida a sus instintos, entonces el desencadenamiento de sus pasiones no conocerá freno y aparecerá lo que en el fondo no ha dejado nunca de ser, "sanguinario y bestial". Por lo tanto, para el agregado militar la única opción para detener al comunismo era la represión, encarnada por la "fría energía" del Ministro del Interior, el General Martínez Anido. Plantear otra solución, incluyendo la instauración de una República, "sería una muestra de un desconocimiento absoluto de la psicología española", porque el día en que se diera al pueblo español, sin preparación para recibirlas, libertades políticas, abusarían y caerían inmediatamente en la anarquía. En fin, parece que la democracia podía ser un régimen apropiado para el pueblo francés, pero desaconsejable, de todo punto, para el español. En conclusión, para el agregado militar de la Francia republicana en España, era preferible la existencia del rey, porque si alguna vez la monarquía desapareciera, el país no tardaría en caer presa del comunismo ${ }^{36}$.

Discurso que reflejaba claramente tanto los tópicos sobre los españoles, como el momento histórico en que se vivía, pues la amenaza bolchevique, poco creíble en España donde los comunistas eran minoritarios (Elorza, Bizcarrondo, 1999; González Calleja, 2005), hacía que las fuerzas conservadoras mirasen hacia el autoritarismo y apostasen por la eliminación de derechos y libertades. Circunstancia que la Dictadura aprovechaba para reivindicarse y hasta ponerse a la altura de "los países más democráticos, como Francia, (que) han prohibido toda manifestación del $1^{\circ}$ de Mayo porque han comprendido que

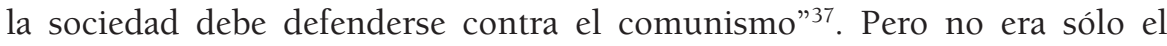
miedo al comunismo lo que afloraba en el informe del agregado militar, sino también los fantasmas provenientes de la I Guerra Mundial. Porque el objetivo de Moscú, según su explicación, no era exclusivamente España, sino principalmente Francia. Así que no dudaba en señalar que había una convergencia, en nuestro país, de intereses de los dos grandes enemigos de Francia: Moscú, por su expansionismo revolucionario, y Berlín, que en su lucha eterna contra Francia intentaba sacar provecho de los desórdenes provocados por los comunistas ${ }^{38}$.

\footnotetext{
${ }^{36}$ Informe secreto del agregado militar de la Embajada de Francia en España, 25-111924. AMAE, serie Z, cartón 240.

${ }^{37}$ De Peretti a Briand, 3-5-1927, en el que recogía un editorial de La Nación, órgano oficial del Régimen. AMAE, serie Z, cartón 240.

${ }^{38}$ Informe secreto del agregado militar de la Embajada de Francia en España, 25-111924. AMAE, serie Z, cartón 240.
} 


\section{El mantenimiento del orden}

A pesar de los "complots" que las potencias extranjeras promovían en España y de los miedos bolcheviques del agregado militar, los informes diplomáticos insistían en la calma del país y el mantenimiento del régimen "en medio de la indiferencia nacional" 39 . Sin embargo, no dejaban de recoger cómo la dictadura iba perdiendo paso a paso la "popularidad" con la que había llegado. Las dificultades económicas que habían aparecido tras la Gran Guerra estaban sintiéndose en la industria, el comercio y la banca. La vida era más cara, mientras que la falta de trabajo y el hambre obligaba a la gente a emigrar en masa ${ }^{40}$. Así que la "indiferencia nacional" que, según el Embajador, permitía mantenerse en el poder a Primo de Rivera, empezaba a ser considerada por la diplomacia francesa como una amenaza. Aunque esta aseveración valiera para toda España, la atención especial se dirigía a Cataluña, que era considerada por la diplomacia francesa, debido a la importante presencia anarquista, como "el Vesubio de España, cuyas erupciones son espaciadas, previstas en general, pero por ello no menos peligrosas" 41 .

Así que los informes de la Embajada no dejaban de mostrar una atención especial al descubrimiento de bombas, detonadores, dinamita y pistolas en Zaragoza o Barcelona ${ }^{42}$; y hacia los atentados contra el Dictador, que desde el gobierno se querían desvincular de la esencia misma del régimen: "dado que Cánovas, el autor de la Constitución del 76, y Canalejas, el portavoz de la democracia, fueron asesinados", los atentados al General no podían atribuirse a su política, sino más bien a la pasión que los gobernantes provocaban en los "desequilibrados" 43 . Pero también mostraban una atención especial a la conflictividad laboral, como los 7.000 obreros metalúrgicos que se declararon en huelga en Bilbao por un incremento salarial ${ }^{44}$; o el conato de huelga general vivido en Barcelona por el impuesto que el gobierno quería cobrar sobre el salario de los obreros, y que provocó paros importantes en la capital y generales en localidades como Sabadell y Tarrasa. Actuaciones que la censura impuesta por el régimen silenciaba ${ }^{45}$.

\footnotetext{
${ }^{39}$ Informe sobre la situación política en España, 1-11-1925. AMAE, serie Z, cartón 240.

${ }^{40}$ Informe de la Sociedad de Estudios e Informaciones Económicas. Correspondencia del Extranjero. España, 20-2-1925. AMAE, serie Z, cartón 240.

${ }^{41}$ Informe de la Embajada sobre la situación política en España, 25-5-1927. AMAE, serie Z, cartón 240.

${ }^{42}$ Informe del Ministerio del Interior francés al Presidente del Consejo. Ministro de Asuntos Exteriores, 19-12-1924. AMAE, serie Z, cartón 267.

${ }^{43}$ De Peretti a Briand, 4-8-1926. AMAE, serie Z, cartón 240.

${ }^{44}$ Informe sobre la situación política en España, 1-11-1925. AMAE, serie Z, cartón 240.

${ }^{45}$ Información para Briand, 6-2-1928. AMAE, serie Z, sig. 124.
} 
Censura que, en el mismo sentido, impedía la llegada de noticias sobre importantes movilizaciones internacionales, como la acontecida por la ejecución de los anarquistas Sacco y Vanzetti en Estados Unidos. Aunque para el Embajador la explicación de la falta de manifestaciones en España era debida no sólo a la ausencia de información sino también a la "firmeza del Directorio contra los sindicalistas de Cataluña y Vizcaya, a la indiferencia e ignorancia del trabajador español, a la organización más profesional que política de la UGT, en fin -contradiciendo al agregado militar-a la falta de influencia de la Tercera Internacional en España y ausencia de relaciones entre Moscú y Madrid"46.

Lo cierto es que todo parece indicar que la represión había surtido su efecto. Las ejecuciones derivadas de sentencias de muerte se habían disparado desde el golpe: de 1920 a 1923 se habían producido 8; mientras que en 1924 y los primeros meses de 1925, las ejecuciones llegaron a $16^{47}$; los "atentados sociales" se habían reducido de forma drástica: de 819 en 1923, a 18 en 1924; mientras que el número de huelgas pasó de 458, con 3 millones de jornadas perdidas en 1923; a 96, con algo más de 300.000 jornadas en 1929 (Villares, Moreno, 2010: 514-517). En cuanto al papel de la UGT, Jean Herbette, Embajador de Francia en Moscú, informaba de la reunión del Bureau Exécutif du Profintern (Internationale des Syndicats Professionals) que, en su sesión del 10 de enero de 1928, abordó la cuestión del sindicalismo en España. En ella se confirmaba el retroceso de la CNT en España, cuya afiliación situaban en torno a los 15.000 ó 20.000 trabajadores, en beneficio de la reformista UGT, con unos 200.000. Según el informe emanado por el Profintern, la actividad de los sindicatos había disminuido en España, por la política de represión del Gobierno, pero también "por la 'traición' de los jefes reformistas"48.

A pesar de todo, los movimientos dirigidos contra la Dictadura aumentaron con la perspectiva de las exposiciones de Barcelona y Sevilla. El régimen pretendía que sirvieran para refutar su política a nivel internacional, por lo que actuó de forma especial contra la oposición. Los informes de la Embajada recogían la importante actividad en Cataluña con el hallazgo de "22 bombas, que no explotaron" en Badalona; la explosión de varias columnas de transmisión eléctrica en Barcelona, Rubí, Igualada y Llimas; la destrucción de un puen-

\footnotetext{
${ }^{46}$ De Montille, encargado de negocios de Francia en España, a Briand, 27-8-1927. AMAE, serie Z, cartón 240 .

${ }^{47}$ De Peretti a Herriot, 24-3-1925, incluye información del Heraldo de Madrid recogida por el Embajador. AMAE, serie Z, cartón 240. Para el problema de los atentados y los jurados populares, véase Herrerín, 1991.

${ }^{48}$ Informe de Jean Herbette al Ministro de Asuntos Exteriores de Francia, 16-1-1928. AMAE, serie Z, sig. 124.
} 
te entre Badalona y Barcelona de la línea férrea que unía con Francia... ${ }^{49}$. Por su parte, en Sevilla se declaró una huelga -por la muerte de una obrera debido a la actuación de la Guardia Civil- al día siguiente del cierre de la Exposición, el 25 de junio, que había dado lugar a enfrentamientos sangrientos entre obreros y la fuerza pública. Huelgas similares, aunque de menor importancia, tuvieron lugar en otras ciudades como Bilbao, Málaga, Córdoba, Granada y Zaragoza $^{50}$.

En fin, la dictadura se encaminaba a su fin. Viejos políticos como el Conde de Romanones, en conversación privada con Thierry, encargado de negocios de Francia en España, mostraba su incertidumbre ya no sólo sobre el futuro del rey o la sucesión al trono, sino incluso de la fidelidad del país a la monarquía ${ }^{51}$. Incertidumbre que también mostraba el Embajador de Francia en Londres, Fleuriau, que esperaba con inquietud lo que deparara a España después de la desaparición de la Dictadura ${ }^{52}$.

\section{Conclusiones}

Francia, que compartía fronteras con España no solo en Europa sino también en África, trató con la España de Primo de Rivera de la misma forma que venía haciendo desde tiempo antes, no como una igual sino desde una posición (y un sentimiento compartido muy marcado) de clara superioridad, tanto por lo que respecta a su cultura como a su poder e influencia internacionales. Los diplomáticos franceses se veían formando parte de una gran potencia colonial asociada a los valores de la democracia, la tolerancia, el laicismo, la racionalidad, obligados a relacionarse con los dirigentes de un país atrasado, clerical, bárbaro, irracional, con el que a regañadientes manifestaron su disposición a entenderse, siempre que éstos aceptasen un papel subordinado. En los años de la Dictadura, España fue tenida en cuenta por Francia únicamente a un nivel regional, en el marco del Mediterráneo occidental, porque su posición en el mapa -sobre el estrecho de Gibraltar, entre dos continentes y dos mares, y con la posesión de las bases navales de Baleares y Canarias- podía hacerla apetecible como aliada por parte de algún potencial enemigo digno de tal nom-

\footnotetext{
${ }^{49}$ Informes sobre la situación en España, 1-5-1929, 7-5-1929 y 4-6-1929. AMAE, serie Z, cartón 240. $\mathrm{n}^{\circ} 151$.

${ }^{50}$ Informe de la Embajada de Francia en España a Briand, 2-7-1930. AMAE, serie Z,

${ }^{51}$ Thierry, encargado de negocios de Francia en España, a Briand, 7-9-1928. AMAE, serie Z, cartón 240.

${ }^{52}$ Fleuriau, Embajador de Francia en Londres, a Briand, 20-2-1929. AMAE, serie Z, cartón 240.
} 
bre. La victoria en la guerra del Rif dio a la Dictadura alas para reclamar un mayor protagonismo y presencia en el área del Estrecho, así que Francia se vio en la necesidad de contemporizar, aunque fuese solo formalmente, y adoptar una actitud vigilante y algo más benévola, para evitar que Primo de Rivera "se echase en brazos" de Mussolini. Las dos penínsulas mediterráneas encarnaron en aquellos años una potencial amenaza de desestabilización del statu quo y era evidente que un pacto político-militar entre ellas habría de revestir un carácter antifrancés, pero en Francia nunca se acabó de creer que el dictador español se atreviese a subvertir la tradicional política española de alianza con la entente franco-británica. A pesar de las acciones extemporáneas del dictador, a pesar de su resistencia a verse tratado como una dócil comparsa, parecían más claros los inconvenientes que las ventajas de romper la relación de dependencia con respecto a la nación con la que España compartía fronteras a ambos lados del Mediterráneo.

Proximidad que para Francia era motivo también de preocupación por el otro gran asunto que, junto a la cuestión marroquí, preocupaba ya no sólo al país galo, sino en general a los gobiernos liberales de Europa: la expansión del comunismo. Aunque la presencia del comunismo en nuestro país fuera en esta época testimonial, y el protagonismo de las fuerzas de izquierdas correspondía en mayor medida a socialistas y anarquistas, lo cierto es que los informes diplomáticos franceses insistían en señalar el peligro comunista que se cernía sobre España. Sin embargo, los documentos emanados en la embajada francesa mostraban un conocimiento claro de la posición de las fuerzas de izquierda preponderantes en nuestro país: socialistas, como colaboradores con la dictadura; y anarquistas, promotores de los principales movimientos huelguísticos y actos de violencia contra el régimen. Así que la identificación de la subversión con el peligro comunista hay que entenderla más en clave interna francesa y en la identificación de un movimiento que, más allá de la ideología, significa la subversión del orden establecido.

A este respecto, los informes diplomáticos franceses, que eran prolíficos en el análisis de la política interior española, bascularon entre la crítica contundente, aunque razonada, de los embajadores, a la visión furibunda, no exenta de apriorismos y tópicos, del agregado militar. Los primeros intentando desentrañar las claves políticas, económicas y sociales de España, así como las características de sus principales protagonistas: el Rey, el dictador, los políticos de la Restauración..., con la advertencia de que uno de los principales problemas de España era que la Restauración no era un régimen democrático; mientras que el segundo se aferraba a la imagen del pueblo analfabeto, primitivo, corrupto, sin formación política, en el que predominaban los instintos 
a la razón, y al que no correspondía otra respuesta, si quería evitarse la victoria bolchevique, que la represión. Miedo a la expansión comunista que, mezclada con los fantasmas de la I Guerra Mundial, mostraba una España como campo de experimento y complot de soviéticos y alemanes que terminaría afectando, tarde o temprano, a su querida patria. En este contexto, las preferencias del agregado militar de la Francia republicana incluía el mantenimiento del rey en España, si con ello se evitaban problemas para su país. Deseo que chocaba con una realidad que dibujaba la incertidumbre ya no sólo sobre el futuro de Alfonso XIII, sino incluso de la de la institución monárquica.

\section{Bibliografía}

ALLAIN, Jean-Claude (1976). Agadir 1911. Un crise impérialiste en Europe pour la conquete du Maroc. París: Publications de la Sorbonne.

BACHOUD, Andrée (1988). Los españoles ante las campañas de Marruecos. Madrid: Espasa-Calpe.

DELAUNAY, Jean Marc (2010). Méfiance cordiale: les relations franco-espagnoles de la fin du XIXe siècle à la Première Guerre Mondiale. vol. 2: Les relations coloniales. Paris: L'Harmattan.

DENÉCHÈRE, Ives (1999). La politique espagnole de la France de 1931 à 1936: une pratique française de rapports inégaux. Paris: L'Harmattan.

ELORZA, Antonio (1972-1974). El anarcosindicalismo español bajo la dictadura (1923-1930). Revista del Trabajo, 39-46, 123-218, 315-617 y 161-463.

ELORZA, Antonio; BIZCARRONDO, Marta (1999). Queridos camaradas. La Internacional comunista y España (1919-1939). Barcelona: Planeta.

GONZÁLEZ CALLEJA, Eduardo (2005). La España de Primo de Rivera. La modernización autoritaria, 1923-1930. Madrid: Alianza Editorial.

HERRERÍN, Ángel (1991). Anarquía, dinamita y revolución social. Violencia y represión en la España de entre siglos (1868-1909). Madrid: Los libros de la catarata.

HERRERÍN, Ángel (2010). De la lucha por la revolución a la defensa de los derechos. El $1^{\circ}$ de Mayo en España a través de sus manifiestos. En RIVAS, Lucía (dir.). El Primero de Mayo en España. 120 aniversario (1890-2010) (69-94). Madrid: Fundación $1^{\circ}$ de Mayo.

JULIÁ, Santos (1997). Los socialistas en la política española, 1879-1982. Madrid: Taurus. LORENZO, Anselmo (1923). El Proletariado Militante (Memorias de un Internacionalista), Libro 2. Barcelona.

MARÍN, José María (1991). Santiago Alba y la crisis de la Restauración (1913-1930). Madrid: UNED.

PALOMARES, Gustavo (1989). Mussolini y Primo de Rivera: politica exterior de dos dictadores. Madrid: Eudema.

RIVAS, Lucía (1987). Historia del 1º de Mayo en España. Desde 1900 hasta la II República. Madrid: UNED. 
SUEIRO SEOANE, Susana (1988). El contencioso de Tánger. El Estatuto de 1923. En Actas del Congreso Internacional "El Estrecho de Gibraltar". Ceuta, noviembre de 1987 (379-396). Madrid.

SUEIRO SEOANE, Susana (1989). La incorporación de Tánger: una batalla perdida de la diplomacia primorriverista (1926-1928). Espacio, Tiempo y Forma. Revista de la Facultad de Geografía e Historia: Historia Contemporánea. V-2, 69-87.

SUEIRO SEOANE, Susana (1992). España en el Mediterráneo: Primo de Rivera y la 'cuestión marroqui', 1923-1930. Madrid: UNED.

SUEIRO SEOANE, Susana (1995). Contrabando en las costas del Rif: armas europeas para Abd-el-Krim. En Actas del II Congreso Internacional "El Estrecho de Gibraltar". Ceuta, noviembre de 1990. Tomo V: Historia Contemporánea (261-269). Madrid.

SUEIRO, Susana (2002). La Dictadura de Primo de Rivera. En AVILÉS, Juan y otros. Historia Política, 1875-1939 (283-306). Madrid: Istmo.

SUEIRO SEOANE, Susana (2005). Le relazioni Spagna-Italia negli anni Venti. En DI FEBO, Giuliana; MORO, Renato (eds.). Fascismo e franchismo: relazioni, immagini, rappresentazioni (29-44). Roma: Rubbettino.

SUEIRO SEOANE, Susana (2013a). La cuestión de Tánger: del estatuto internacional a la ocupación española. En Ceuta y el Norte de África entre dos dictaduras (19231945). XIV Jornadas de Historia de Ceuta (127-150). Ceuta: Instituto de Estudios Ceutíes.

SUEIRO SEOANE, Susana (2013b). La política exterior de la Dictadura de Primo de Rivera en el contexto autoritario de los años 20. En FORNER MUÑOZ, Salvador (coord.). Coyuntura internacional y política española (1898-2004) (65-80). Madrid: Biblioteca Nueva.

TUSELL, Javier; SAZ, Ismael (1982). Mussolini y Primo de Rivera: las relaciones políticas y diplomáticas de dos dictaduras mediterráneas. Boletín de la Real Academia de la Historia, CLXXIX, 413-484.

VILLARES, Ramón; MORENO, Javier (2009). Restauración y Dictadura, vol. de FONTANA, Josep; VILLARES, Ramón (dirs.). Historia de España. Madrid: Crítica/Marcial Pons. 